\title{
Voice and hyperthyroidism: Subjective voice complaints and alterations of the acoustic parameters of the voice
}

\author{
Gordana Kovacic* \\ Croatian radiotelevision, Announcers department, Zagreb, Croatia
}

\begin{abstract}
The influence of thyroid gland dysfunction on voice is barely investigated, particularly the influence of hyperthyroidism. The aim of the study was to investigate the voices of 18 female subjects with hyperthyroidism (mean age 38.2 years) by means of objective voice analysis. The phonation of the vowel /a/ was acoustically analyzed by PRAAT computer program. Additionally, laryngeal and respiratory efficiency was examined by means of maximum phonation/friction time tests. Subjects were asked about subjective voice complaints. The differences in means of objective measurement variables between subjects reporting voice complaints and subjects without complaints were statistically analyzed by the method of $t$-tests for independent samples. The objective measurement findings showed laryngeal inefficiency and suggest possible laryngeal pathology and dysphonia, with low vocal fundamental frequency being the most remarkable characteristic. Half of the subjects reported subjective voice complaints. Lowered voice pitch and hoarseness were among the most frequent and are in concordance with objective measurement findings. No significant difference was observed between the two samples of subjects on any objective measurement variable. In conclusion, hyperthyroidism does affect voice. Lowering of the voice pitch and reduced laryngeal efficiency are clinical symptoms of hyperthyroidism.
\end{abstract}

\section{Introduction}

Optimally efficient vocalization requires the production of consistent voice quality throughout wide fundamental frequency and intensity ranges. In order to accomplish that skill, the anatomic and neurobiological properties of the organs of respiration, phonation, resonance and articulation must be optimal. There are numerous factors that may affect voice production, one of them being endocrine imbalance. The endocrine-related effects are associated with changes in fluid accumulation within the connective tissue of the vocal fold lamina propria, the result of which are mass changes of the vocal folds and changes in their geometry and mechanical properties [1].

The thyroid gland produces the thyroid hormone which controls a number of metabolic and physiologic processes, and regulates tissue metabolism and protein synthesis [2,3]. It also plays a major role in voice production $[4,5]$. The lack of sufficient thyroid hormone in the body known as hypothyroidism generates weakness, lethargy, intolerance to cold, puffiness around the eyes, and voice changes such as dysphonia, monotonous voice, lower voice pitch, and decreased voice range $[4,5,6]$. Whereas excessive secretion of the thyroid hormone or hyperthyroidism causes hyperkinesia, elevated blood pressure, rapid pulse, bulging eyes, sweating, weight loss, general weakness and fatigue [7]. Features of pathological voice quality, i. e. dysphonia related to hyperthyroidism are barely mentioned. However, one may suspect that general weakness and fatigue reflect on laryngeal and respiratory musculature causing asthenic voice quality or other dysphonic feature, or vocal fatigue (phonasthenia). One method that can provide useful objective data is acoustic analysis of the voice. This method will be employed in the present study. Additionally, respiratory-phonatory tests will be carried out as to exam respiratory and laryngeal efficiency.

Another purpose of the study is to explore subjective voice complaints and test whether there are differences in objective measurement variables between subjects with complaints and those with no subjective complaints. Thus, two hypotheses were proposed: (H1) the acoustic characteristics of the voice and laryngeal efficiency in subjects suffering from hyperthyroidism are not within average (normative) ranges, and (H2) there are significant differences in acoustic characteristics of the voice and laryngeal efficiency between subjects with subjective voice complaints and those without such complaints.

\section{Subjects and methods}

A total of 18 subjects, all females, were assessed. Participation requirement included medical history on hyperthyroidism. Subjects' average age was 38.2 years, ranging from 20 to 56 . They were under medical therapy for 9.72 months as an average, ranging from no therapy to 36 months of therapy. There were 8 smokers and 10 non-smokers. None of the subjects suffered from cold or other respiratory infection at the time of the data collection. None of the subject was professional voice user. The participation in the study was on a voluntary basis.

Prior to voice recording, all subjects went through an interview, where a short questionnaire assessing information on age, smoking status, medical problems, length of the therapy related to hyperthyroidism, and subjective voice complaints was completed.

Correspondence to: Gordana Kovacic, Klekova 11, 10110 Zagreb, Croatia, E-mail: gordana.kovacic@inet.hr

Key words: voice, hyperthyroidism, acoustic analysis, subjective voice complaints, vocal fundamental frequency $F_{0}$, voice pitch

Received: February 23, 2018; Accepted: March 21, 2018; Published: March 24, 2018 
Voice recordings were made in one and the same silent room. The cardioid microphone Electro Voice N/D157B and mini-disc recorder Sony MZ-R35 were used. The distance between subject's mouth and microphone was $16 \mathrm{~cm}$. Subjects were asked to phonate the prolonged vowel /a/ at comfortable pitch and loudness. This vocal task was repeated three times by each subject so that the mean for each acoustic feature is calculated later on.

The acoustic analysis was performed using PRAAT software developed by Paul Boersma and David Weenink [8]. The middle onesecond portion of each vowel production was analyzed. The following variables were extracted: fundamental frequency $\mathrm{F}_{0}$, sound pressure level SPL, jitter (fundamental frequency perturbation) and harmonicto-noise ratio HNR. Vocal rise time VRT was selected manually from the waveform and measured in milliseconds (ms). It was measured from the onset of voice to the point at which the sound wave achieved the mean amplitude of the steady part of the phonation [9].

Having on mind possible poor coordination between the respiratory and phonatory musculature, a set of respiratory-phonatory variables was added to acoustic variables. These are maximum phonation time MPT, maximum friction time MFT and s/z-ratio. MPT and MFT tests measure the longest duration of phonation of the voiced consonant $/ \mathrm{z} /$ and friction of the voiceless consonant $/ \mathrm{s} /$, respectively. The subjects were instructed to produce /s/ and /z/ with smooth and steady voice, each in one single breath for three times. The longest performance (time) was taken into statistical analyses. S/z-ratio is calculated as MFT to MPT ratio.

The data were statistically analyzed on the descriptive level using Statistical Package for the Social Sciences. The differences in means between subjects with subjective voice complaints and those without such complaints were tested by a method of t-test for independent samples. $\mathrm{P}$ value $<0.05$ was considered statistically significant.

\section{Results and discussion}

The data for each subject including means of measured variables and specified subjective voice complaint(s) are shown in Table 1. Half of the subjects reported subjective voice complaints where hoarseness and lower voice pitch were among the most frequent. Self-reported vocal fatigue may be related to general body fatigue being common clinical feature among patients with hyperthyroidism. Means, standard deviations, minimum and maximum values for all variables are shown in Table 2. Each will be discussed separately.

\section{Vocal fundamental frequency $F_{0}$}

Fundamental frequency $\mathrm{F}_{0}$ is a physical parameter that defines the rate of the vocal fold vibrations and describes a basic property of the voice - its pitch. The lower the $\mathrm{F}_{0}$, the lower the voice pitch, and vice versa. The $\mathrm{F}_{0}$ of an adult female voice falls within $200-220 \mathrm{~Hz}$ range. Table 2 shows that mean $\mathrm{F}_{0}$ is below average $(172.44 \mathrm{~Hz})$, and that nearly half of the subjects showed remarkably low $\mathrm{F}_{0}$ falling within range $140-168 \mathrm{~Hz}$ (Table 1). Such low $\mathrm{F}_{0}$ is usually seen in mechanical dysphonia.

\section{Jitter}

Jitter or frequency perturbation measures the degree of instability in the cycle-to-cycle vibratory pattern of the vocal folds [10]. More than $1 \%$ jitter is an indication of vocal pathology both for male and female voices [11]. The voices with jitter percent greater than 1 are usually perceived as hoarse [12]. The results of this study showed mean jitter value $1.33 \%$ (Table 2). Even though jitter is considered to be strong vocal health indicator, one must not rely on it solely when making professional judgment about the voice.

\section{Vocal rise time VRT}

Vocal rise time VRT, defined as duration of the interval between the initiation of phonation and the point at which waveform reaches stable amplitude, gives the information on phonation onset quality. Vocal rise time within range $18-50 \mathrm{~ms}$ refers to hard (glottal) onset, whereas vocal rise time above $150 \mathrm{~ms}$ is registered in breathy (aspirate) phonation onset [9]. In this study, mean value was $49.6 \mathrm{~ms}$ (Table 2) suggesting hard vocal onset or attack. Such voice onset quality is nor desirable nor healthy. It is characterized by adduction of the vocal chords prior to the airflow and is usually observed in hyperkinetic dysphonia. Inspection of individual results (Table 1) shows that in minority of subjects balanced or coordinated phonation onset is found.

\section{Sound pressure level SPL and harmonic-to-noise ratio HNR}

Sound pressure level SPL and harmonic-to-noise ratio HNR showed mean value of $77.2 \mathrm{~dB}$ and $20.34 \mathrm{~dB}$, respectively (Table 2). Due to the fact that amplification of the signal was not controlled, SPL and HNR absolute values cannot be solely interpreted, but are taken for the purpose of comparison of the two groups of subjects, those with vocal complaints and others without complaints.

\section{Maximum phonation time MPT, maximum friction time MFT and s/z ratio}

Maximum duration of production of the sustained sibilants /s/ (MFT variable) and /z/ (MPT variable) measures respiratory and phonatory efficiency, respectively. The ratio of MFT to MPT, so called $\mathrm{s} / \mathrm{z}$ ratio, provides information on laryngeal efficiency [1]. The $\mathrm{s} / \mathrm{z}$ ratio about 1 reflect normal efficiency [13]. However, each MFT and MPT value has to be considered alone as well. It is expected that adults perform 20-25 seconds MFT and MFT. S/z ratio greater than 1.4 with normal MFT, but reduced MPT indicates laryngeal inefficiency with increased air leakage during phonation due to incomplete glottal closure. The greater the $\mathrm{s} / \mathrm{z}$ ratio, the greater the possibility of laryngeal dysfunction or pathology. The subjects of this study showed $\mathrm{s} / \mathrm{z}$ ratio 1.32 , with normal MPT and MFT.

The above-mentioned findings confirm the first hypothesis (H1) that the acoustic characteristics of the voice and laryngeal efficiency in patients with hyperthyroidism fall outside normal ranges.

\section{Testing the differences in means of objective variables between patients with subjective voice complaints and those without complaints}

Half of the subjects in this study reported voice complaints where hoarseness and lowered voice pitch were among the most frequent (Table 1). Means (M), standard deviations (SD), and independent samples t-test for all variables in subjects with vocal complaints and those without complaints are shown in Table 3. No significant difference was observed between the two samples of subjects on any variable, thus the second hypothesis (H2) failed. However, the variables deserving attention are s/z ratio being 1.45 and percent jitter 1.52 in subjects with voice complaints both indicating laryngeal inefficiency and possible vocal fold pathology. This $\mathrm{s} / \mathrm{z}$ ratio finding is in concordance with assumptions on weakness and the poor coordination between breathing and phonation levels in hyperthyroid patients [5,14].

The finding of no significant differences between the two samples of subjects defined by presence or absence of subjective voice complaints shows that all patients with hyperthyroidism share similar acoustic 
Table 1. Personal, acoustic and respiratory-phonatory data for the female hyperthyroid patients $(\mathrm{N}=18)$

\begin{tabular}{|c|c|c|c|c|c|c|c|c|c|c|c|c|}
\hline $\mathbf{N}$ & $\begin{array}{c}\text { Age } \\
\text { (years) }\end{array}$ & $\begin{array}{l}\text { Therapy } \\
\text { (months) }\end{array}$ & Smoking & $\begin{array}{c}\mathbf{F}_{0} \\
(\mathbf{H z})\end{array}$ & $\begin{array}{l}\text { SPL } \\
\text { (dB) }\end{array}$ & $\begin{array}{l}\text { VRT } \\
(\mathrm{ms})\end{array}$ & $\begin{array}{c}\text { jitter } \\
(\%)\end{array}$ & $\begin{array}{l}\text { HNR } \\
\text { (dB) }\end{array}$ & $\begin{array}{c}\text { MFT } \\
\text { (s) }\end{array}$ & $\begin{array}{l}\text { MPT } \\
\text { (s) }\end{array}$ & $\begin{array}{l}\mathbf{s} / \mathbf{z} \\
\text { ratio }\end{array}$ & $\begin{array}{l}\text { Subjective voice } \\
\text { complaints }\end{array}$ \\
\hline 1. & 20 & 6 & No & 197 & 82 & 79 & 0.60 & 17 & 22 & 14 & 1.57 & Lower pitch, hoarseness. \\
\hline 2. & 28 & 12 & No & 204 & 77 & 30 & 1.00 & 22 & 19 & 22 & 0.86 & Lower pitch, hoarseness. \\
\hline 3. & 29 & - & Yes & 167 & 75 & 39 & 0.78 & 23 & 44 & 36 & 1.22 & No complaints. \\
\hline 4. & 29 & 12 & No & 179 & 78 & 44 & 1.9 & 21 & 30 & 24 & 1.25 & Lower pitch, softer voice. \\
\hline 5. & 30 & 2 & Yes & 177 & 83 & 19 & 1.00 & 24 & 20 & 15 & 1.33 & No complaints. \\
\hline 6. & 33 & 12 & No & 166 & 75 & 39 & 0.71 & 21 & 36 & 34 & 1.06 & No complaints. \\
\hline 7. & 34 & - & Yes & 168 & 74 & 28 & 0.86 & 21 & 45 & 26 & 1.73 & Lower pitch, hoarseness. \\
\hline 8. & 36 & 12 & No & 196 & 73 & 20 & 1.56 & 18 & 25 & 25 & 1.00 & No complaints. \\
\hline 9. & 37 & 12 & No & 178 & 72 & 75 & 1.20 & 18 & 36 & 22 & 1.64 & No complaints. \\
\hline 10. & 39 & 12 & Yes & 192 & 75 & 48 & 0.26 & 24 & 21 & 16 & 1.31 & Lower pitch, hoarseness. \\
\hline 11. & 39 & 12 & No & 168 & 76 & 74 & 5.85 & 12 & 21 & 16 & 1.31 & Fatigue, rarely aphonia. \\
\hline 12. & 39 & 12 & Yes & 146 & 80 & 68 & 0.49 & 24 & 29 & 18 & 1.61 & Hoarseness. \\
\hline 13. & 43 & 2 & Yes & 156 & 73 & 64 & 0.83 & 20 & 23 & 21 & 1.10 & Hoarseness. \\
\hline 14. & 47 & - & Yes & 140 & 80 & 63 & 2.37 & 19 & 21 & 20 & 1.05 & No complaints. \\
\hline 15. & 47 & 18 & No & 201 & 81 & 44 & 1.86 & 15 & 35 & 15 & 2.33 & Voice fatigue, hoarseness. \\
\hline 16. & 51 & 36 & Yes & 180 & 82 & 5 & 0.38 & 28 & 44 & 46 & 0.96 & No complaints. \\
\hline 17. & 51 & 3 & No & 140 & 78 & 82 & 1.74 & 18 & 23 & 22 & 1.05 & No complaints. \\
\hline 18. & 56 & 12 & No & 149 & 76 & 23 & 0.53 & 23 & 20 & 15 & 1.33 & No complaints. \\
\hline
\end{tabular}

Table 2. Means (M), standard deviations (SD), minimum (Min), and maximum values (Max) for the acoustic and respiratory-phonatory variables for the female hyperthyroid patients (N=18)

\begin{tabular}{|c|c|c|c|c|}
\hline Variable & $\mathbf{M}$ & SD & Min & Max \\
\hline Age / years & 38.22 & 9.54 & 20.00 & 56.00 \\
\hline Therapy / months & 9.72 & 8.64 & 0.00 & 36.00 \\
\hline $\mathrm{FO} / \mathrm{Hz}$ & 172.44 & 20.63 & 140.00 & 204.00 \\
\hline $\mathrm{SPL} / \mathrm{dB}$ & 77.22 & 3.44 & 72.00 & 83.00 \\
\hline $\mathrm{VRT} / \mathrm{ms}$ & 46.9 & 23.5 & 5 & 82 \\
\hline Jitter / \% & 1.33 & 1.28 & 0.26 & 5.85 \\
\hline $\mathrm{HNR} / \mathrm{dB}$ & 20.44 & 3.80 & 12.00 & 28.00 \\
\hline $\mathrm{MFT} / \mathrm{s} / / \mathrm{s}$ & 28.56 & 9.17 & 19.00 & 45.00 \\
\hline $\mathrm{MPT} / \mathrm{z} / / \mathrm{s}$ & 22.61 & 8.55 & 14.00 & 46.00 \\
\hline $\mathrm{s} / \mathrm{z}$ ratio & 1.32 & 0.36 & 0.86 & 2.33 \\
\hline
\end{tabular}

Table 3. Means $(M)$, standard deviations $(S D)$, and independent samples $t$-test results in comparing female hyperthyroid patients with subjective voice complaints (N=9) and patients with no complaints $(\mathrm{N}=9)$ based on acoustic and respiratory-phonatory variables

\begin{tabular}{|c|c|c|c|c|c|c|c|c|c|}
\hline \multirow{2}{*}{ Variable } & \multicolumn{2}{|c|}{ With complaints } & \multicolumn{2}{|c|}{ No complaints } & \multicolumn{2}{|c|}{ Levene's test } & \multirow{2}{*}{ t-test } & \multirow{2}{*}{ DF } & \multirow{2}{*}{ P value } \\
\hline & $\mathbf{M}$ & SD & $\mathbf{M}$ & SD & $\mathbf{F}$ & p & & & \\
\hline Age, years & 35.33 & 8.41 & 41.11 & 10.19 & 1.446 & 0.247 & 1.312 & 16 & 0.208 \\
\hline $\mathrm{F} 0, \mathrm{~Hz}$ & 179 & 20.8 & 165.89 & 19.37 & 0.186 & 0.672 & -1.382 & 16 & 0.185 \\
\hline SPL, dB & 77.33 & 3.16 & 77.11 & 3.88 & 0.642 & 0.435 & -0.081 & 16 & 0.896 \\
\hline VRT, ms & 53.22 & 18.72 & 40.55 & 27.09 & 1.183 & 0.293 & -1.154 & 16 & 0.265 \\
\hline jitter, \% & 1.52 & 1.72 & 1.14 & 0.65 & 2.031 & 0.173 & -0.614 & 16 & 0.548 \\
\hline $\mathrm{HNR}, \mathrm{dB}$ & 19.56 & 4.09 & 21.33 & 3.46 & 0.225 & 0.642 & 1.012 & 16 & 0.335 \\
\hline MPT, s & 19.11 & 4.28 & 26.11 & 10.46 & 5.882 & 0.027 & 1.858 & 16 & 0.082 \\
\hline MFT, s & 27.22 & 8.5 & 29.89 & 10.12 & 1.425 & 0.25 & 0.606 & 16 & 0.553 \\
\hline $\mathrm{s} / \mathrm{z}$ ratio & 1.45 & 0.43 & 1.18 & 0.22 & 2.238 & 0.154 & -1.701 & 16 & 0.108 \\
\hline
\end{tabular}

features of the voice, that is, in the direction of laryngeal dysfunction and dysphonia. However, in order to better understand complex nature of the hyperthyroid voice, more studies need to be conducted with various objective voice measurements applied, and with more detailed inspection of the subjective voice complaints.

\section{Conclusion}

The study confirmed that female subjects diagnosed with hyperthyroidism show alterations of acoustic parameters of voice in the direction of laryngeal dysfunction where finding of low fundamental frequency $F_{0}$, that is deep voice, is the most remarkable and should be added to clinical features of hyperthyroidism. Subjective voice complaints were reported by half of the subjects of the study. The most frequent were lowered voice pitch and hoarseness corresponding to findings based on objective voice analysis. In these subjects raised $\mathrm{s} / \mathrm{z}$ ratio and jitter values suggest laryngeal pathology.

Further studies focused on laryngeal status and clinical voice evaluation in hyperthyroid patients seem relevant as to reveal not only how hyperthyroidism affects vocal organ and its function, but also what can be done in order to reduce negative effects by means of voice therapy, i. e. voice hygiene being a part of the core hormonal therapy. This is particularly important when dealing with patients who are professional voice users and whose both personal and professional well-being depends greatly on vocal status. 


\section{References}

1. Sataloff RT (1991) Endocrine dysfunction. In: Sataloff RT, editor. Professional voice: The science and art of clinical care. New York: Raven Press, Ltd 201-205.

2. LeFevre ML (2015) Screening for thyroid dysfunction: U.S. preventive services task force recommendation statement. Ann Intern Med 162: 641-650. [Crossref]

3. Benninger MS (1994) Medical disorders in the vocal artist. In: Benninger MS, Jacobson $\mathrm{BH}$, Johnson AF, editors. Vocal arts medicine - the care and prevention of professional voice disorders. New York: Thieme Medical Publishers, Inc 177-215.

4. Hari Kumar KVS, Ajaj Chandr NS, Singh SP, Datta R (2016) Voice and endocrinology. Indian J Endocrinol Metab 20: 590-594. [Crossref]

5. Aronson AE (1990) Clinical voice disorders. New York, Thieme Inc.

6. Levine HL (1994) Disorders of singing. In: Benninger MS, Jacobson BH, Johnson AF, editors. Vocal arts medicine - the care and prevention of professional voice disorders. New York: Thieme Medical Publishers, Inc; 163-168.

7. Lazarus JH (1997) Hyperthyroidism. Lancet 349: 339-343. [Crossref]
8. Boersma P, Weenink D (2011) PRAAT-doing phonetics by computer [software]. Version 5.2.16.

9. Baken RJ (1987) Clinical measurement of speech and voice. San Diego/London: Singular Publishing Group, Inc.

10. Jacobson BH (1994) Objective voice analysis: the clinical voice laboratory. In Benninger MS, Jacobson BH, Johnson AF, editors. Vocal arts medicine - the care and prevention of professional voice disorders. New York: Thieme Medical Publishers, Inc.; 135-152.

11. Deem JF, Manning WH, Knack JV, Matesich JS (1989) The automatic extraction of pitch perturbation using microcomputer: some methodological consideration. $J$ Speech Hear Res 32: 689-697. [Crossref]

12. Seikel JA, King DW, Drumright DG (1997) Anatomy and physiology for speech and language. San Diego - London: Singular Publishing Group, Inc.

13. Shipley GK, McAfee JG (1992) Assessment in speech-language pathology - a resource manual. San Diego, CA: Singular Publishing Group, Inc.

14. Damste PH, Lerman JW (1975) An introduction to voice pathology, functional and organic. Springfield, Illinois: Charles C Thomas.

Copyright: $(2018$ Kovacic G. This is an open-access article distributed under the terms of the Creative Commons Attribution License, which permits unrestricted use, distribution, and reproduction in any medium, provided the original author and source are credited. 